\title{
SNAPSHOT
}

\section{Siphoning for safety}

A cheap and simple piece of equipment could be the answer to a natural hazard in the high mountains of Asia. Glacial lakes are at danger of bursting and threaten lives and property. The pairing of Som Gurung, of the Royal University of Bhutan, with Stephen Hughes and Les Dawes, both from the Science and Engineering Faculty and Institute for Future Environments, Queensland University of Technology, sparked the idea of using Hughes's earlier work on siphons for water movement in natural systems (Phys. Educ. 45, 162-166; 2010) to address this serious problem.

Increased temperatures globally are causing glacier retreat, and the meltwater is filling and expanding the glacial lakes, potentially leading to glacial lake outburst floods. Glacial lakes vary in size and their walls are often formed by the moraine soil and rock debris, up to boulder size, which has been pushed along by the glacier edge. The outburst floods can be triggered by a breakdown of the natural dam wall or by an avalanche of rock or snow displacing large volumes of water from the lake. These events can come at a high cost. In October 1994, glacial lake Lugge Tsho in northern Bhutan experienced an outburst flood when the moraine dam wall failed due to increased melt water pressure (Mt. Res. Dev. 16, 77-81; 1996). Without warning, the 18 million cubic metres of flood water reached the village of Punakha, approximately $86 \mathrm{~km}$ downstream, causing massive damage and resulted in the loss of 21 lives.

"Currently there are 26 glaciers [in Bhutan] at risk [of an outburst flood] and there may be several more" said Hughes. Work is being done to reduce the risk of outburst floods, but it is dangerous and labour intensive. Teams of people work with simple tools, moving rocks and debris to facilitate controlled drainage and reduce lake water levels (Nature 461, 1042-1046; 2009, and UNDP http://go.nature.com/ HI7qvl).

The use of siphons to lower lake levels offers a safer alternative and a more permanent solution. A siphon, or a number of siphons, can be installed

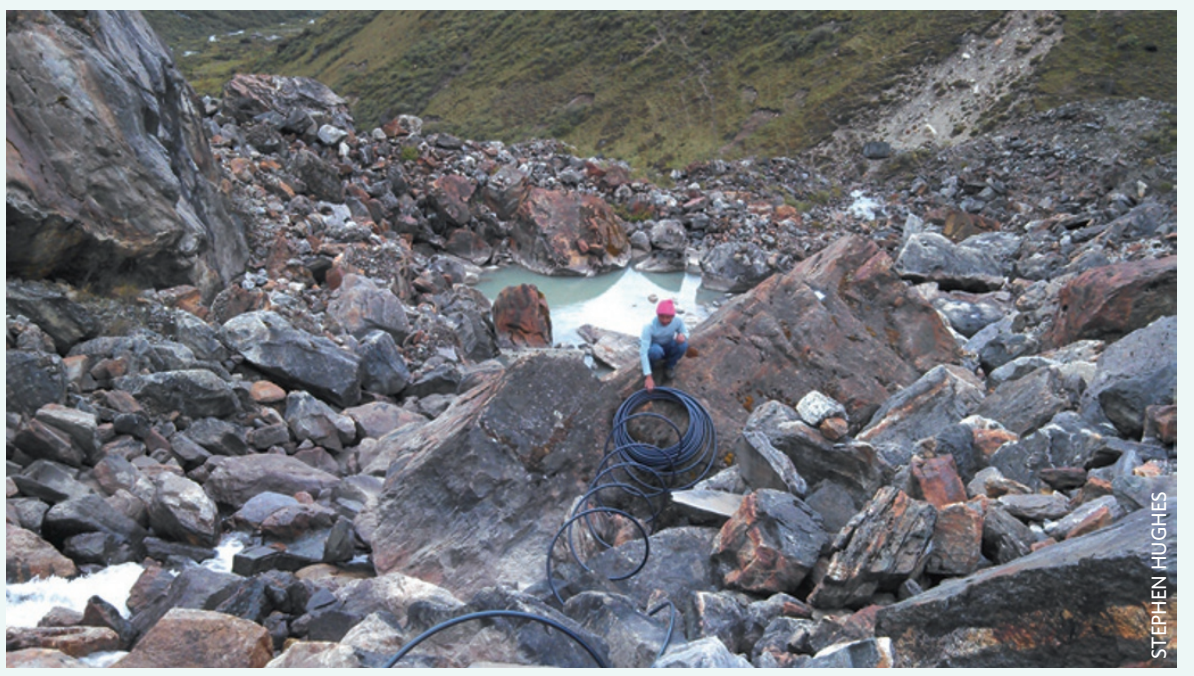

in a lake and can be turned on and off as needed. Installing multiple siphons would allow greater drainage while requiring smaller diameter tubing; this also reduces the impact of blockage or failure of any individual siphon. Careful positioning of the outlet pipe, into the main glacial river or broadly dispersed through use of a trumpet, would prevent the water build-up hazard from being transferred downstream. There would be no need to remove the hosing over the winter, meaning the system would remain ready to be switched on when the melt season begins.

In September 2013, Hughes, Gurung, Dawes and support staff travelled $35 \mathrm{~km}$ on foot to a test lake, situated 4,200 $\mathrm{m}$ above sea-level on one of the highest mountains in Bhutan. The purpose of this trip was to prove that the siphons could be deployed successfully in a remote location where all equipment and supplies needed to be transported by pony. The entire trip was achieved on a budget of AUD $\$ 1,600-$ including equipment and sustenance for six people. The low-cost makes the technique a realistic option for impoverished regions. In fact, it offers another benefit - the possibility for small-scale hydroelectric power generation. Nepal is already using mini-scale hydropower, so the technology is available. It could bring electricity to remote areas where they currently get by without power, except what is generated by small solar panels.

The project hopes to use local companies for materials and local people for installation and operation. Hughes noted that "the best model would be to train local people, such as yak farmers, to actually start the siphons at the start of the summer once the melt commences." The team was joined by a yak farmer, who was working in the area, last September.

At the moment, there isn't funding for the project to move forward. "We need AUD\$100,000 for the next test stage, which will be conducted on a lake that is currently 100 m deep", Hughes commented. The lake was suggested by Karma Toeb, chief glaciologist of Bhutan, who is in collaboration with the team. The lake is located further into the mountains and would require a 5-6 day hike, transporting a greater amount of equipment as they hope to install a number of siphons along the lake wall. Overall, the cost of the project could be as low as a few hundred thousand Australian dollars, with minimal ongoing costs. This project highlights how adapting established techniques can provide solutions to emerging hazards as the climate changes.

BRONWYN WAKE 